ASEAN Journal of Chemical Engineering 2021, Vol. 21, No. 2, 241 - 248

\title{
Artificial Neural Network [ANN] Analysis of Co-pyrolysis of Waste Coconut Husk and Laminated Plastic Packaging
}

\author{
Joselito A. Olalo *
}

Department of Mechanical Engineering, College of Engineering, Camarines Norte State College, Daet, Camarines Norte, 4600, Philippines

*e-mail: joselitoolalo@cnsc.edu.ph

Submitted 02 October 2021

Revised 09 November $2021 \quad$ Accepted 11 November 2021

Abstract. Co-pyrolysis of plastic with biomass was used in the possible mitigation of environmental health problems associated with plastic waste. The pyrolysis method possessed the highest solution in the reduction of waste problems. Fuel oil can be produced through the pyrolysis of plastic and biomass waste. Many researchers used pyrolysis technology to produce a suitable amount of pyrolytic oil through different optimization techniques. This study will predict the percentage mass oil yield using an artificial neural network. It uses an input layer, hidden layer and an output layer. Three input factors for the input layer were (i) temperature, (ii) particle size, and (iii) percentage coconut husk. The structure has one hidden layer with two neurons. The artificial neural network was designed to predict the percentage oil yield after 15 pyrolysis runs set by the Box-Behnken design of the experiment. Percentage oil yields after pyrolysis were calculated. Results showed that temperature and percentage of coconut husk significantly influenced the percentage oil yield. Predicted values from simulation in the artificial neural network showed a good agreement through a correlation coefficient of $99.5 \%$. The actual percentage oil yield overlaps the predicted values, which ANN demonstrates as a viable solution.

Keywords: Artificial neural network, Co-pyrolysis, Coconut husk, Laminated plastic

\section{INTRODUCTION}

From the year 1950 to 2050, a predicted 33 billion tons of plastic will be circulated (UNEP, 2016). These were from an average increase of at least $10 \%$ annually. Municipal waste was commonly comprised of LDPE, PP, PS and PET in every household (APME, 2015). Recent estimates show that at least 8 million MT/year of plastics were brought to the oceans, and the Philippines was among the top 10 countries as sources of mismanaged plastic wastes reaching the ocean. Plastic was about $10 \%$ of the wastes in dumpsites and sanitary landfills. On top of this, 1.88 million
MT of mismanaged plastics were from the Philippines. The increasing amount of residual wastes (laminated plastic packaging), i.e., non-recyclable, was a pressing concern in the country because the existing landfills were full, and land area was limited in urban areas, where these wastes mainly were generated. Moreover, some of the wastes, mostly plastics, were illegally disposed of in streams and eventually ended in seas, resulting in marine life problems and eventual degradation of nature (Jambeck et al., 2015).

Various recycling methods were done to reduce volumes of waste in dumpsites but possess to be labor-intensive (Co and Paringit 
242 Artificial Neural Network (ANN) Analysis of Co-pyrolysis of Waste Coconut Husk and Laminated Plastic Packaging

2021). One of them was the pyrolysis process, which converted this waste and was used as an alternative fuel (Olalo 2021, Olalo 2022). A better output was produced, emitting lesser NOx and SOx emissions when combusted (Saffarzadeh et al., 2006). Biomass can be used as a co-pyrolyzing feedstock with plastics to lessen plastics' effects, which can be dangerous to human health. While biomass was significant with the co-pyrolysis with plastics, it can also help in the energy recovery process (Caroko et al., 2020).

Biomass such as agricultural waste can be a potential resource because of its ability to be degraded in environmentally-friendly methods (Costa et al., 2021). There were limited studies on pyrolysis of coconut husk, and there were no studies yet on co-pyrolysis of coconut husks and single-use laminated plastic packaging (LPP). The influences of process conditions, such as temperature, particle size and material proportion, among others, on pyrolysis of coconut husk alone, real assorted mixtures of single-use LPP alone, and co-pyrolysis of coconut-husk and biomass-LPP were not known. Artificial neural network analysis or ANN modelling was very powerful in predicting output with a given data set, especially in a very complex structure (Shihani et al., 2006). Like how our human brain works, synapses made the most interconnected neurons predict various values (Sohl et al., 1995).

The neural network was a black-box model, and in the real world, the input and output parameters were visible. Neural networks were proven to be accurate as compared to statistical methods. However, it cannot display how the input variables behave and influence the target output (Galang and Ballesteros, 2018). Feedstock mixture, i.e., the ratio of coconut husk to plastics, was expected to affect the yield of the pyrolytic oil because the two feedstocks were of different compositions and properties. The effect of particle size was yet to be determined on the heat transfer and rate of pyrolysis. This study aimed to determine the predicted percentage oil yield, i.e., feedstock composition, particle size and operating temperature, for batchwise co-pyrolysis of coconut husk and plastic laminates, using Artificial Neural Network (ANN). Correlation, to the highest degree, was the advantage of ANN to the other statistical methods such as the response surface methodology (RSM) (Gupta et al., 2015). In this study, an artificial neural network (ANN) was used to analyze the correlation conditions of the co-pyrolysis of $\mathrm{CH}$ and waste plastic LPP with regards to the \% yield oil produced.

\section{MATERIALS AND METHODS}

\section{Work Plan}

There were two parts employed in this study. First (1) was the batch co-pyrolysis runs and the second (2) was the artificial neural network analysis.

\section{Batch Co-Pyrolysis Runs}
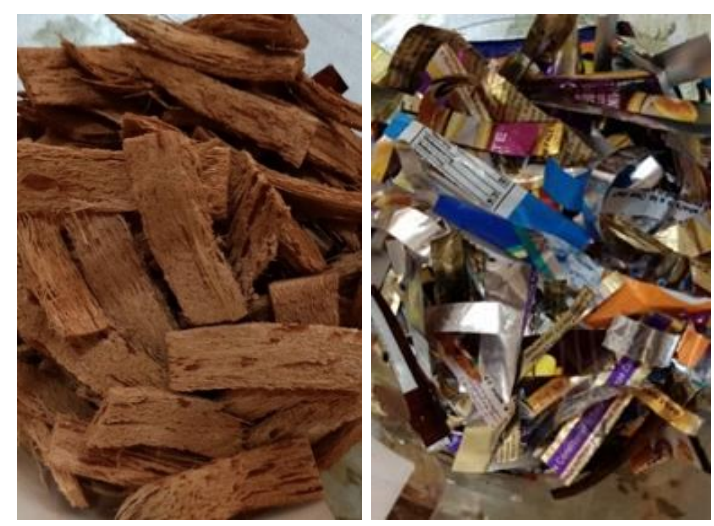

Fig. 1: The Coconut Husk $(\mathrm{CH})$ and Laminated Plastic Packaging (LPP) 
Batch co-pyrolysis runs were performed at various $\mathrm{CH}$ and LPP blends, temperatures, and particle sizes, particularly a Box-Behnken experiment design. The output parameter was oil yield in the batch runs. Coconut husk and waste laminated plastic packaging (LPP) were obtained from different waste disposal sites. They were cleaned, dried (air-dried), as shown in Figure 1. The feedstocks were cut into $1 \mathrm{~cm}, 3 \mathrm{~cm}$, and $5 \mathrm{~cm}$ particle sizes for the batch pyrolysis experiments. The $\mathrm{CH}$ :LPP volume proportions were 40:60, 50:50 and 60:40 proportion. The corresponding mass percent of coconut husks were $32 \%, 42 \%$ and $51 \%$, respectively. The total masses of the mixtures were $170 \mathrm{~g}, 164 \mathrm{~g}$ and $176 \mathrm{~g}$, respectively. The density of $\mathrm{CH}$ and LPP were 1.4 $\mathrm{g} / \mathrm{cc}$ and $2 \mathrm{~g} / \mathrm{cc}$, respectively. The LPP in the blends were $50 \%$ of shampoo sachet and $50 \%$ of food packaging, which contains a thin layer of aluminum foil.

To determine the effects of the process parameters $\% \mathrm{CH}$, temperature and particle size on the response parameters mass oil yield, several batch pyrolysis runs were performed as shown in Table 1.

The pyrolysis system consists of an electrically-heated reactor where the feedstock was placed at the start of the run (see Figure 2). A constant heating rate of $20^{\circ} \mathrm{C} / \mathrm{min}$ was used until the temperature reached the individual response parameters of $500{ }^{\circ} \mathrm{C}, 600^{\circ} \mathrm{C}$ and $700^{\circ} \mathrm{C}$ with the residence time of 30 minutes.

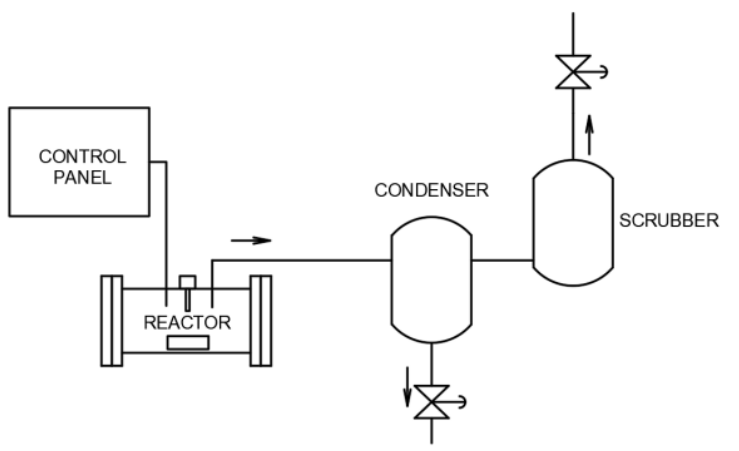

Fig. 2: The Pyrolysis System Experimental Set Up

Table 1. Batch Pyrolysis Process Conditions According to The Box-Behnken Response Surface Design of Experiment

\begin{tabular}{|c|c|c|c|c|c|c|c|}
\hline $\begin{array}{c}\text { Run } \\
\text { number }\end{array}$ & $\begin{array}{c}\text { Tempera- } \\
\text { ture } \\
\left({ }^{\circ} \mathrm{C}\right)\end{array}$ & $\begin{array}{c}\text { Particle } \\
\text { size } \\
(\mathrm{cm})\end{array}$ & $\begin{array}{c}\text { Feedstock } \\
\text { composition } \\
\text { (\% coconut } \\
\text { husk) }\end{array}$ & $\begin{array}{c}\text { Run } \\
\text { number }\end{array}$ & $\begin{array}{l}\text { Tempera- } \\
\text { ture }\left({ }^{\circ} \mathrm{C}\right)\end{array}$ & $\begin{array}{c}\text { Particle } \\
\text { size } \\
(\mathrm{cm})\end{array}$ & $\begin{array}{c}\text { Feedstock } \\
\text { composition } \\
\text { (\% coconut } \\
\text { husk) }\end{array}$ \\
\hline & A & B & C & & A & B & C \\
\hline 1 & 500 & 1 & 42 & 9 & 600 & 1 & 32 \\
\hline 2 & 700 & 1 & 42 & 10 & 600 & 5 & 32 \\
\hline 3 & 500 & 5 & 42 & 11 & 600 & 1 & 51 \\
\hline 4 & 700 & 5 & 42 & 12 & 600 & 5 & 51 \\
\hline 5 & 500 & 3 & 32 & $13^{\mathrm{a}}$ & 600 & 3 & 42 \\
\hline 6 & 700 & 3 & 32 & $14^{\mathrm{a}}$ & 600 & 3 & 42 \\
\hline 7 & 500 & 3 & 51 & $15^{\mathrm{a}}$ & 600 & 3 & 42 \\
\hline 8 & 700 & 3 & 51 & & & & \\
\hline
\end{tabular}


244 Artificial Neural Network (ANN) Analysis of Co-pyrolysis of Waste Coconut Husk and Laminated Plastic Packaging

Gases and volatile substances coming from the reactor went to a condenser where condensable substances were condensed. The condenser was cooled using running cold water. The condensed oil was collected, and some non-condensable gas passed to a scrubber. When the residence time was reached, the reactor will be shut-off to allow slow cooling. Another batch run will be done after the reactor's temperature was reduced to a tolerable level.

After pyrolysis, the oil was collected from the specified number of runs given in Table 1. Eq. (1) was used to calculate the mass oil yield.

$$
\% \text { Yield }=\frac{\text { weight of produced oil }}{\text { weight of feedstock }}
$$

\section{Artificial Neural Networks Analysis}

Artificial neural network analysis will optimize and correlate the effects of the different input variables in the output variable, which was the percent mass yield of oil. Input variables will be temperature, particle size and percentage composition. Using Visual Gene Developer (VGD) 1.9 software, a predicted value can be generated with the available data sets. This software can construct the structure and neural network analysis and prediction maps to easily locate the weights of each input variable.

The architecture of ANN in this research was a feed-forward neural network (FFNN) with a topology of 3-2-1 using a sigmoid activation function to every output neuron (see Figure 3). In designing a neural network, the hard part was to produce the optimal layers and number of neurons to produce accurate results (Karsoliya 2012). The degree of validity was determined to measure the accurateness of the artificial neural network model.

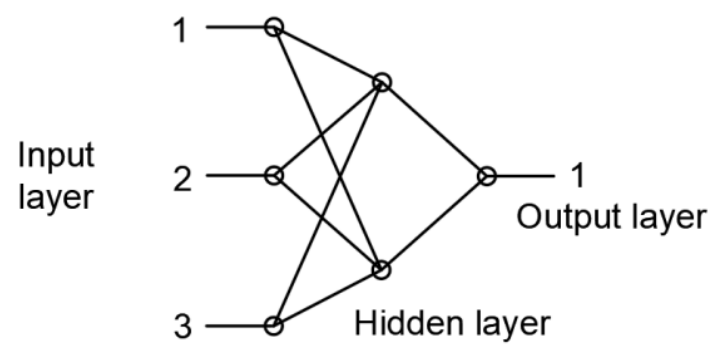

Fig. 3: Structure of The Neural Network Model

Before starting the training process, data sets were first normalized to shorten the distance between the predictors. The training settings were used as shown in Table 2, then proceeded to the training process. It uses a maximum 1 billion training cycle with 0.00001 target error. During the back-propagation, the system was continuously updating the weight values until the desired error in the output was achieved.

Table 2. Training Settings During The Data Training Process

\begin{tabular}{cccccc}
\hline $\begin{array}{c}\text { Learning } \\
\text { rate }\end{array}$ & $\begin{array}{c}\text { Momentum } \\
\text { Coefficient }\end{array}$ & $\begin{array}{c}\text { Transfer } \\
\text { Function }\end{array}$ & $\begin{array}{c}\text { Maximum No. } \\
\text { of Training cy- } \\
\text { cle }\end{array}$ & $\begin{array}{c}\text { Target } \\
\text { Error }\end{array}$ & $\begin{array}{c}\text { Analysis } \\
\text { Update } \\
\text { Interval } \\
\text { (cycle) }\end{array}$ \\
\hline 2.0 & 0.1 & Sigmoid & $1,000,000,000$ & $1^{-5}$ & 500 \\
\hline
\end{tabular}


Table 3. Percentage Mass Oil Yield

\begin{tabular}{ccccc}
\hline $\begin{array}{c}\text { Run } \\
\text { number }\end{array}$ & $\begin{array}{c}\text { Temperature } \\
\left({ }^{\circ} \mathbf{C}\right)\end{array}$ & $\begin{array}{c}\text { Particle size } \\
(\mathbf{c m})\end{array}$ & $\begin{array}{c}\text { Feedstock } \\
\text { Composition } \mathbf{( \% ~ C H ) ~}\end{array}$ & $\begin{array}{c}\text { Actual Oil } \\
\text { Yield (\%) }\end{array}$ \\
\hline 1 & 500 & 1 & 42 & 19.72 \\
2 & 700 & 1 & 42 & 25 \\
3 & 500 & 5 & 42 & 20 \\
4 & 700 & 5 & 42 & 30.5 \\
5 & 500 & 3 & 32 & 20.17 \\
6 & 700 & 3 & 32 & 25.5 \\
7 & 500 & 3 & 51 & 10.2 \\
8 & 700 & 3 & 51 & 25.17 \\
9 & 600 & 1 & 32 & 27.5 \\
10 & 600 & 5 & 32 & 31.17 \\
11 & 600 & 1 & 51 & 18.33 \\
12 & 600 & 5 & 51 & 13.98 \\
13 & 600 & 3 & 42 & 24.1 \\
14 & 600 & 3 & 42 & 23.4 \\
15 & 600 & 3 & 42 & 22.2 \\
\hline
\end{tabular}

\section{RESULTS AND DISCUSSION}

\section{Experimental Percentage Oil Yield}

Table 3 presents the percentage of oil yield in each run. The highest $\%$ oil yield of $31.17 \%$ occurred in temperature of $600{ }^{\circ} \mathrm{C}, 5$ $\mathrm{cm}$ particle size and $32 \% \mathrm{CH}$ and was caused by the large particle size and the high percentage of LPP. And the lowest was $10.2 \%$ oil yield in $500^{\circ} \mathrm{C}$ temperature, $3 \mathrm{~cm}$ particle size and $51 \% \mathrm{CH}$. A higher amount of $\mathrm{CH}$ will cause the oil yield to increase.

In batch co-pyrolysis of $\mathrm{CH}$ and LPP, oil yield was directly influenced by temperature and $\% \mathrm{CH}$. Within the experimental temperature range, oil yield is higher at higher temperatures and lower \%CH.

\section{ANOVA Results}

Oil yield increases with temperature increase (within the experimental range 500 $700^{\circ} \mathrm{C}$ ), while it decreases with a $\% \mathrm{CH}$ increase. Thus, the oil yield is favored at higher temperatures and lower percent of coconut husk. The effect of particle size on the output percentage oil yield produced a weak positive correlation of $8.49 \%$. Using Analysis-of-Variance (ANOVA), a model with $\mathrm{P}<0.05$ was deemed significant (Kilic et al., 2014). ANOVA results of Table 3 showed a significant model with a P-value of 0.0386 .

\section{Predicted Oil Yield via ANN}

Using the neural network, figure 4 presents the actual percentage oil yield and the estimated or predicted percentage oil yield. At this point, the efficiency of the model has 
246 Artificial Neural Network (ANN) Analysis of Co-pyrolysis of Waste Coconut Husk and Laminated Plastic Packaging

been validated. The results showed that the data obtained using neural network have a margin of error of $\pm 0.12 \%$.

With only one hidden layer, the VGD 1.9 software achieved a sum of square \pm 0.00001 with a correlation accuracy of $99.5 \%$. This accuracy of the neural network method was encouraging, but it relied on the input data's accuracy as well.

Due to the small margin of errors, the actual percentage oil yield overlapped the predicted values in the graph. In this case, neural networks demonstrated a feasible solution to solve a non-linear problem which was advantageous to statistical methods. The ANN modelling's superiority over the statistical model was justified. ANN forms a complex relationship between the input and output variables producing minimum prediction error (Gupta et al., 2015), which was not attainable by statistical method (Mia and Dhar, 2016).

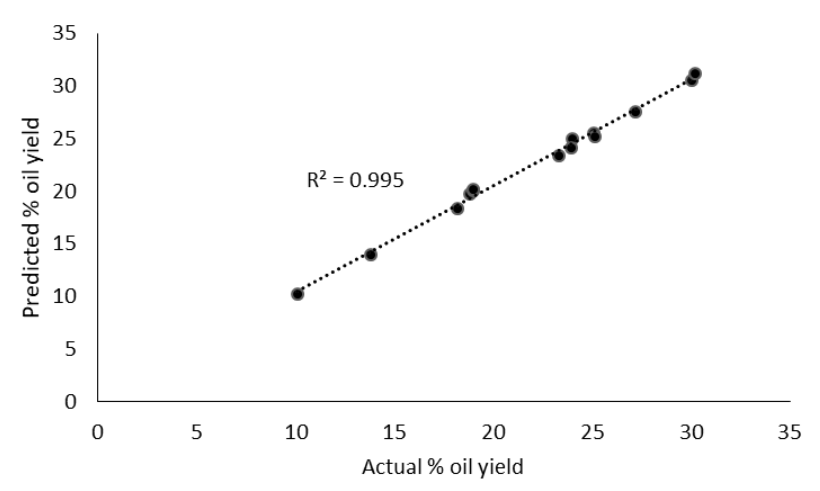

Fig. 4: Actual versus Predicted Percentage Oil Yield

The model has established synaptic connections between the input, hidden and output neurons during the training process. This connection contains different weight values needed in the prediction. VGD 1.9 Software is limited to providing the actual value of weight. However, a neural network map analysis is provided, as shown in figure 5. Figure 5 shows the weight of the synapse connected to every neuron with the aid of VGD 1.9 software. This diagram provided insight into variable importance by visually examining the weights between the neuron layers. The legend indicates that near the "red" color, the weight value was approaching a positive value, whereas, near the "violet" color, the weight is approaching a negative value.

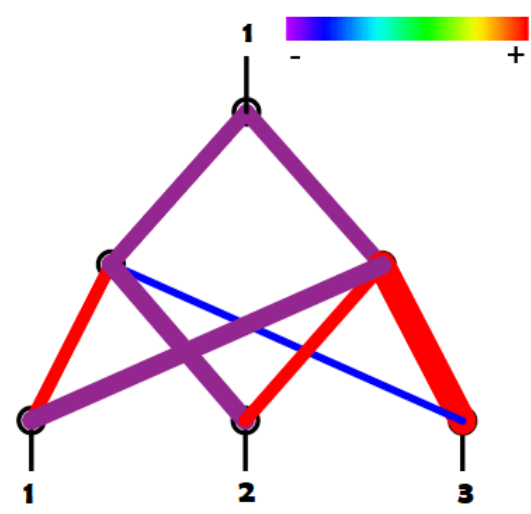

Fig. 5: Neural Network Map Analysis

Table 4. Predicted Percentage Oil Yield Results via ANN

\begin{tabular}{cc}
\hline $\begin{array}{c}\text { Run } \\
\text { number }\end{array}$ & $\begin{array}{c}\text { Predicted Oil Yield } \\
\text { (\%) via ANN }\end{array}$ \\
\hline 1 & 18.8 \\
2 & 24 \\
3 & 19 \\
4 & 30.05 \\
5 & 19 \\
6 & 25.1 \\
7 & 10.12 \\
8 & 25.1 \\
9 & 27.2 \\
10 & 30.2 \\
11 & 18.2 \\
12 & 13.8 \\
13 & 23.94 \\
14 & 23.3 \\
15 & 22.1 \\
\hline
\end{tabular}


The results from the neural networks are presented in Table 4. It was noticed that the optimum value to get the highest predicted oil yield of $30.2 \%$ was at the temperature of $600{ }^{\circ} \mathrm{C}, 5 \mathrm{~cm}$ particle size and $32 \% \mathrm{CH}$ (see corresponding Table 3). These numbers were produced after the de-normalization of the resulting predicted values using simulation in the artificial neural network.

\section{CONLUSIONS}

This study looked into the potential of co-pyrolysis as a means of converting waste single-use laminated plastic packaging and coconut husk to liquid fuel. Overall, this study elucidated the factors influencing the process and how the co-pyrolysis process of these specific waste materials behaves concerning percentage oil yield.

This study produced an $\mathrm{R}^{2}$ of $99.5 \%$ correlation accuracy between percentage oil yield results in the actual experiment and ANN prediction. The ANN prediction model demonstrated a feasible solution to a nonlinear problem. Therefore, it is recommended that the input factors be further explored for more realistic estimates. The training settings in Visual Gene Developer 1.9 software can also be improved to obtain a faster learning process.

\section{ACKNOWLEDGEMENT}

The researcher expresses gratitude for the utmost support of DOST-ERDT in funding the research.

\section{REFERENCES}

1. Association of Plastic Manufacturers Europe (APME) (2015). An analysis of European plastics production, demand and waste data. Belgium: European Association of Plastics Recycling and Recovery Organisations, p. 1-32.

2. Caroko, N., Saptoadi, H., \& Rohmat, T.A. (2020). Heating Characteristics of Palm Oil Industry Solid Waste and Plastic Waste Mixture using a Microwave. ASEAN J.Chem.Eng., 20 (2), 174-183.

3. Co, R.A.S., \& Paringit, E.C. (2021). The Regional Assessment on the Solid Wasteto-Energy Potential in the Island of Luzon, Republic of the Philippines. Chemical Engineering Transactions, 83, 457462.

4. Costa, P., Pinto, F., Mata, R., Marques, P., Paradela, F., \& Costa, L. (2021). Validation of the Application of the Pyrolysis Process for the Treatment and Transformation of Municipal Plastic Wastes. Chemical Engineering Transactions, 86, 859-864.

5. Galang, M.G.K., \& Ballesteros, Jr. F. (2018). Estimation of waste mobile phones in the Philippines using neural networks. Global NEST Journal, Vol 20, No 4, pp 767-772.

6. Gupta, A.K., Guntuku, S.C., Desu, R.K., \& Balu, A. (2015). Optimization of turning parameters by integrating genetic algorithm with support vector regression and artificial neural networks. Int J Adv Manuf Technol 77(1-4):331-9.

7. Jambeck, J.R., Geyer, R., Wilcox, C., Siegler, T.R., Perryman, M., Andrady, A., ... \& Law, K.L. (2015). Plastic waste inputs from land into the ocean. Science, 347(6223), 768-771.

8. Karsoliya S. (2012). Approximating number of hidden layer neurons in multiple hidden layer BPNN architecture. Int J Eng Trends Technol 3(6):713-7.

9. Kılıc, M., Pütün, E., \& Pütün, A.E. (2014). Optimization of Eu phorbia ri gida. fast 
248 Artificial Neural Network (ANN) Analysis of Co-pyrolysis of Waste Coconut Husk and Laminated Plastic Packaging

pyrolysis conditions by using response surface methodology. J. Anal. Appl. Pyrolysis 110: 163-171.

10. Mia, M., \& Dhar, N.R. (2016). Response surface and neural network based predictive models of cutting temperature in hard turning. Journal of Advanced Research, 7(6), 1035-1044.

11. Olalo, J. (2021). Characterization of Pyrolytic Oil Produced from Waste Plastic in Quezon City, Philippines Using Non-catalytic Pyrolysis Method. Chemical Engineering Transactions, 86, 1495-1500.

12. Olalo, J. (2022). Pyrolytic Oil Yield from Waste Plastic in Quezon City, Philippines: Optimization Using Response Surface Methodology. International Journal of Renewable Energy Development, 11(1), 325-332.

13. Saffarzadeh, A., Shimaoka, T., Motomura, Y., \& Watanabe, K. (2006). Chemical and mineralogical evaluation of slag products derived from the pyrolysis/melting treatment of MSW. Waste Manage, 26, 1443-1452.

14. Shihani, N., Kumbhar, B.K., \& Kulshreshtha, M. (2006). Modeling of extrusion process using response surface methodology and artificial neural networks. J. Eng. Sci. Technol. 1 31-40.

15. Sohl, J.E., \& Venkatachalam, A.R. (1995). A neural network approach to forecasting model selection. Information and Management, 29(6), 297-303.

16. UNEP (2016). Marine plastic debris and microplastics - Global lessons and research to inspire action and guide policy change. United Nations Environment Programme, Nairobi. 